Gut, 1972, 13, 596-603

\title{
The effects of different bile salts on the absorption of fluid, electrolytes, and monosaccharides in the small intestine of the rat in vivo
}

\author{
J. T. HARRIES ${ }^{1}$ AND G. E. SLADEN
}

From the Department of Gastroenterology, St Bartholomew's Hospital, London

SUMMARY The effects of different bile salts on the absorption of fluid, electrolytes, and monosaccharides have been investigated in the rat small intestine in vivo. In the jejunum, deoxycholate $(1 \mathrm{mM})$ impaired absorption of water and potassium, but not of sodium or glucose; at higher concentrations $(2.5$ and $5 \mathrm{mM})$ secretion of fluid and electrolytes occurred, and glucose and fructose absorption was impaired. By contrast, in the ileum, $1 \mathrm{mM}$ deoxycholate failed to inhibit fluid and electrolyte absorption, and a concentration of $10 \mathrm{mM}$ was required completely to inhibit absorption; secretion was not observed in the ileum.

Chenodeoxycholate $(5 \mathrm{mM})$ produced a similar effect to deoxycholate on fluid and electrolyte absorption in both jejunum and ileum, but taurocholate $(5 \mathrm{mM})$ and taurodeoxycholate $(5 \mathrm{mM})$ were ineffective.

In jejunum, cholate, taurocholate, and taurodeoxycholate, each at a concentration of $5 \mathrm{mM}$, were less effective inhibitors of glucose transport than deoxycholate; chenodeoxycholate failed to inhibit glucose absorption.

Deoxycholate produced histological damage at $5 \mathrm{mM}$, but not at lower concentrations. The functional and structural abnormalities were shown to be reversible phenomena.

These findings may be relevant to the pathogenesis of diarrhoea in patients with bacterial overgrowth in the small intestine.

It is well established that certain bile salts inhibit the absorption of fluid and electrolytes in the large intestine of both the experimental animal and man (Forth, Rummel, and Glasner, 1966; Mekhjian and Phillips, 1970; Mekhjian, Phillips, and Hofmann, 1971), but less is known of their effects in the small intestine, particularly in vivo (Pope, Parkinson, and Olsen, 1966; Teem and Phillips, 1972). In a series of recent communications Gracey and colleagues (Gracey, Burke, and Oshin, 1971a, b; Gracey, Burke, Oshin, Barker, and Glasgow, 1971c) reported on the inhibitory effects of certain bile salts on monosaccharide absorption, but to our knowledge no studies have been reported in which the effects of these compounds on fluid, electrolyte, and monosaccharide absorption have been investigated simultaneously in the small intestine in vivo.

'Present address: Department of Child Health, Institute of Child Health, Guilford Street, London, WC1.

Received for publication 16 June 1972.
This paper presents the results of the first part of a study designed to investigate the effects of different bile salts on the absorption of fluid, electrolytes, and monosaccharides in the small intestine of the rat in vivo. The results have been reported elsewhere in abstract form (Harries and Sladen, 1971).

\section{Methods}

All experiments were performed under light ether anaesthesia in male Wister rats weighing between 250 and $300 \mathrm{~g}$ following a 12-18-hour period of fasting; water was allowed ad lib during the period of fasting. A closed-loop technique was used utilizing the proximal and distal $20-30 \mathrm{~cm}$ of jejunum and ileum respectively. The initial solutions were buffered to a $p \mathrm{H}$ of 7.5 with phosphate $(16 \mathrm{mM})$ and were isotonic (approximately $285 \mathrm{mOsm} / \mathrm{kg}$ of water); the concentrations of sodium, potassium, and chloride used injejunum were 140,4 , and $114 \mathrm{mM}$ 
respectively, and in ileum 150,4 , and $124 \mathrm{mM}$ respectively. In addition, the jejunal solutions contained $20 \mathrm{mM}$ glucose or fructose. The sodium salts of the bile acids were used (Maybridge Research Chemicals, Launceston, Cornwall) and their purity was checked by thin-layer chromatography. Before instilling the solution the loops were washed by rinsing with normal saline and air, and residual saline was removed by gentle manipulation. The solutions were instilled into the jejunal and ileal loops for absorptive periods of 20 and 30 minutes respectively, during which time the abdominal cavity was closed and the body temperature maintained at $36-38^{\circ} \mathrm{C}$. Sodium and potassium were determined in initial and final solutions by flame photometry, chloride by coulometrictitration, glucose by the glucose oxidase method, and fructose by the method of Roe, Epstein, and Goldstein (1949) incorporating certain modifications recommended by Hers, Beaufays, and de Duve (1953) and simplified as described by Mahy, Rowson, Salaman, and Parr (1964).

Polyethylene glycol (PEG) was found to be an unsatisfactory marker for calculating water absorption in the experimental model used because of incomplete recovery of the marker. A known concentration of PEG ( $3 \mathrm{~g} /$ litre) was instilled into jejunal and ileal loops for periods of 20 and 30 minutes respectively; at the end of these periods the loops were emptied and then washed in isotonic saline; PEG concentrations in the fluid remaining in the loops after 20 and 30 minutes, and in the saline washings, were determined by the turbidometric method of Hyden (1956). The volumes of the PEG-containing solutions were recorded, and thus total PEG recoveries could be calculated: in jejunum recovery of the marker varied between 77.8 and $84.7 \%$, mean $81.3 \%(n=6)$, and in ileum the values were $78 \cdot 5-93.1 \%$, mean $89.2 \%(n=6)$. In view of this a weighing technique was developed. The initial volume was determined by weighing the syringe before and after instilling the solutions into the loop (weight 1). Following the 20- or 30-minute absorptive periods, the animal was killed and the intestinal segment dissected free from attached mesentery and removed from the abdomen. The serosal surface of the intact loop was dried by gentle blotting and the loop weighed on a torsion balance (weight 2). The loop was then opened, its contents transferred for subsequent analyses, and the incision continued longitudinally so as to expose the whole mucosal surface which was dried by gentle blotting and weighed again (weight 3 ). The segment was stripped of any attached mesentery and the wet weight of the segment under study measured (weight 4). To minimize any fluid evaporation, the procedure was always performed within a few minutes of killing the animal. Net fluid absorption was calculated as follows:

Absorption in $\mathrm{ml}$ per 20 or 30 minutes per $\mathrm{g}$ wet weight of jejunum or ileum respectively = Weight 1-(weight 2-weight 3)/Weight 4.

Net absorptive rates for monosaccharides and electrolytes were calculated from the difference in their concentrations in the instilled solution and in the fluid at the end of the absorptive periods, and expressed in a similar way to water absorption.

The reversibility experiments performed in jejunum were as follows: after the 20-minute absorptive periods, the bile salt-containing loops and control loops were emptied and gently rinsed with normal saline. Control solutions were then introduced either immediately or following a two-to-three-hour period of recovery during which the animals were kept lightly anaesthetized. Absorption rates were measured as already described.

The significances of the differences between each series of experiments were calculated by both parametric (Wilcoxon's sum of ranks and signed rank test) and non-parametric (paired and unpaired $t$ test) methods, and the $P$ values given in the text represent the lowest value obtained with the two methods of calculation.

In certain experiments the solution under study was instilled into additional loops, and immediately before killing these loops were washed with saline and then dissected out and fixed in formalin for subsequent histology.

\section{Results}

JEJUNUM

The values (mean and standard error) for water absorption at different concentrations of deoxycholate are shown in Fig. 1, and the values for the other bile salts in Figure 2. In addition to water, Table I shows the results obtained for sodium and potassium absorption.

At $0.5 \mathrm{mM}$ deoxycholate there was no difference in water or sodium absorption compared with the control animals, whereas at $1.0 \mathrm{mM}$ significant inhibition of water absorption occurred (for water $P=0.002$; sodium $P=0.05$ ) and, at the two higher concentrations, frank secretion of both water and sodium was observed. The other unconjugated dihydroxy bile salt, chenodeoxycholate, produced a similar effect to deoxycholate at a concentration of $5 \mathrm{mM}$ (Figure 2, Table I).

The response to the other three bile salts (each at a concentration of $5 \mathrm{mM}$ )was in marked contrast to that found with equimolar concentrations of deoxycholate or chenodeoxycholate (Figure 2, 


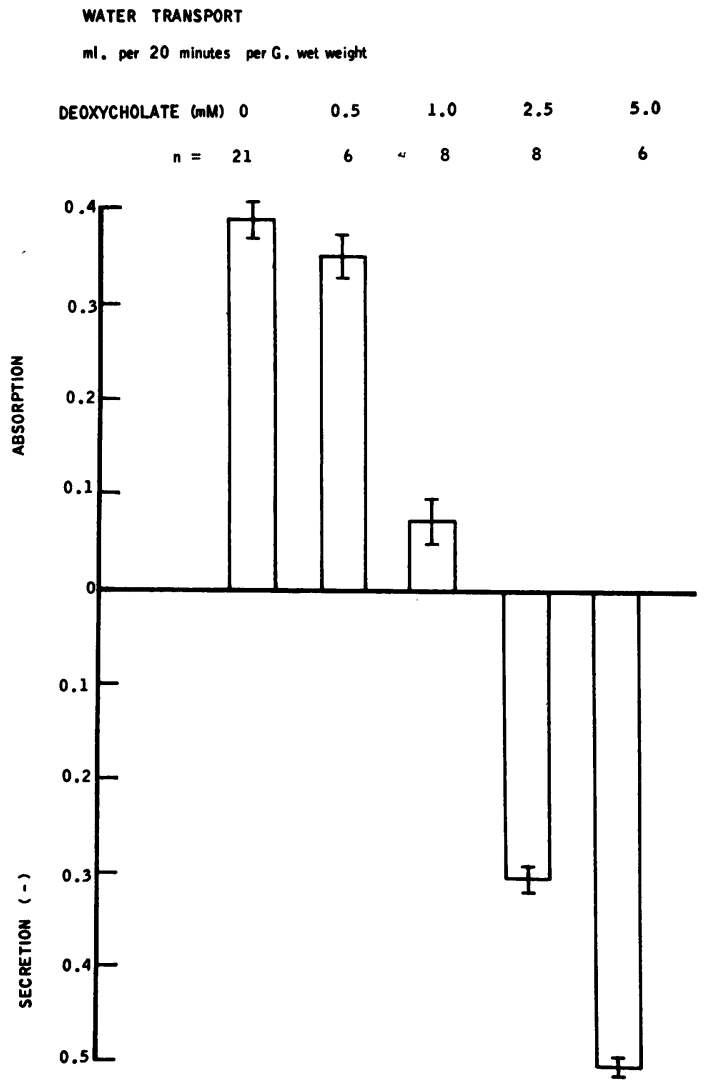

Fig. 1

Table I). Neither taurocholate or taurodeoxycholate significantly impaired the absorption of sodium or water; although mean absorption rates for water were appreciably less with taurodeoxycholate compared with those in the controls (Fig. 2), the difference just failed to reach a level of statistical significance $(P>0.05<0 \cdot 1)$. Free cholate produced slight inhibition of water and sodium absorption $(P=0.05)$.

In both jejunum and ileum net movement of potassium was virtually absent (Tables I and III) in the control animals, presumably because the concentrations used in initial solutions $(4 \mathrm{mM})$ were almost identical to the serum values fround $(4 \cdot 4 \pm 0.15 \mathrm{mM} ; \mathrm{n}=7)$. In jejunum, significant secretion of potassium occurred with all three concentrations of deoxycholate, chenodeoxycholate, and cholate, but this was not the case for taurodeoxycholate.

Chloride absorption in controls $(n=6)$ was $+24 \cdot 3 \pm 8 \cdot 2 \mu$-equiv/20 minutes/g wet weight; both $2.5 \mathrm{mM}(\mathrm{n}=8)$ and $5 \mathrm{mM}(\mathrm{n}=4)$ deoxycholate

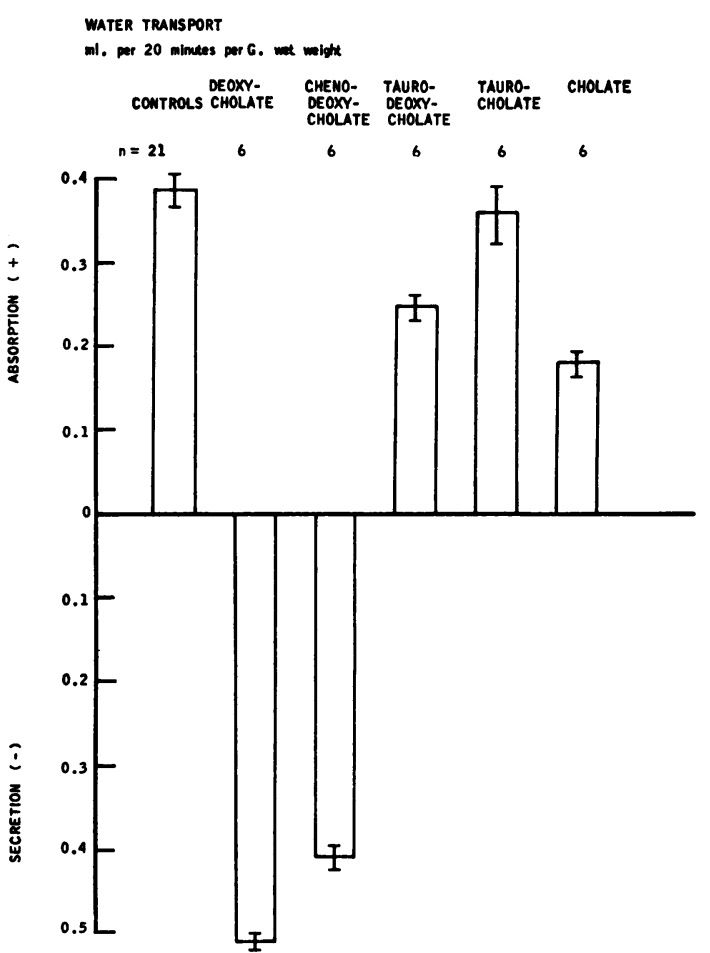

Fig. 2

Fig. 1 Effects of different concentrations of deoxycholate on water transport in jejunum (mean $\pm 1 S E$; $n=$ number of observations).

Fig. 2 Effects of different bile salts (each at $5 \mathrm{mM}$ ) on water transport in jejunum (mean $\pm 1 S E ; n=$ number of observations).

produced secretion of chloride ion, the values being $-50 \cdot 1 \pm 4 \cdot 8$ and $-85 \cdot 8 \pm 9 \cdot 1$ respectively; these values are not significantly different $(P$ by paired $t$ test $>0.05$ ) from the sodium secretory rates at the same two concentrations of deoxycholate (Table I).

Transport of glucose and fructose (Table II) was inhibited to a similar extent by $5 \mathrm{mM}$ deoxycholate $(P<0.002)$. The effect on glucose transport was still present at $2.5 \mathrm{mM}$, but in contrast to fluid absorption, no inhibition could be demonstrated at $1 \mathrm{mM}$ deoxycholate. Cholate $(P<0.05)$, taurocholate $(P=0.01)$, and taurodeoxycholate $(P=0.05)$ were less effective in inhibiting glucose absorption and, surprisingly, chenodeoxycholate failed to cause any significant inhibition.

\section{ILEUM}

At $1 \mathrm{mM}$ deoxycholate, an inhibitory concentration in jejunum, there was no impairment of fluid or electrolyte absorption (Table III). Although 


\begin{tabular}{|c|c|c|c|}
\hline \multirow[t]{2}{*}{ Initial Solutions ${ }^{1}$} & \multicolumn{3}{|c|}{ Absorption per 20 Minutes per Gram Wet Weight of Jejunum ${ }^{2}$} \\
\hline & Water $(m l)$ & Sodium ( $\mu /$ equiv) & Potassium ( $\mu /$ equiv) \\
\hline $\begin{array}{l}\begin{array}{l}\text { Controls } \\
\text { Deoxycholate } \\
(5 \mathrm{mM}) \\
\qquad(2.5 \mathrm{mM}) \\
(1.0 \mathrm{mM}) \\
(0.5 \mathrm{mM})\end{array} \\
\begin{array}{l}\text { Chenodeoxycholate } \\
\text { Cholate }\end{array} \\
\text { Taurocholate } \\
\text { Taurodeoxycholate }\end{array}$ & $\begin{array}{l}+0.39 \pm 0.04(21) \\
-0.51 \pm 0.02 \\
-0.31 \pm 0.03(8) \\
+0.07 \pm 0.05(8) \\
+0.35 \pm 0.05 \\
-0.41 \pm 0.03 \\
+0.18 \pm 0.03 \\
+0.36 \pm 0.07 \\
+0.25 \pm 0.03\end{array}$ & $\begin{array}{l}+53.66 \pm 10.02(12) \\
-86.15 \pm 13.07 \\
-35.45 \pm 6.73(9) \\
+17.44 \pm 6.61(7) \\
+41.58 \pm 8.20 \\
-73.33 \pm 5.61 \\
+23.23 \pm 4.57 \\
+55.78 \pm 13.09 \\
+29.36 \pm 6.44(5)\end{array}$ & $\begin{array}{l}-1.48 \pm 0.45(11) \\
-10.73 \pm 0.81 \\
-5.47 \pm 0.33(9) \\
-5.91 \pm 0.65(9) \\
- \\
-8.93 \pm 0.56 \\
-3.33 \pm 0.22(7) \\
-\overline{-2.66} \pm 0.29(5)\end{array}$ \\
\hline
\end{tabular}

Table I Effects of different bile salts on fluid and electrolyte absorption in the jejunum

${ }^{1}$ All initial solutions contained $20 \mathrm{mM}$ glucose; chenodeoxycholate, cholate, taurocholate, and taurodeoxycholate were each present in a concentration of $5 \mathrm{mM}$.

${ }^{2}+=$ net absorption, $-=$ net secretion; values given in means \pm 1 standard error. Number of observations shown in brackets: where not stated this number is 6 .

\begin{tabular}{|c|c|c|}
\hline \multirow[t]{2}{*}{ Initial Solutions } & \multicolumn{2}{|c|}{ Absorption (mMoles per 20 minutes per Gram Wet Weight of Jejunum) } \\
\hline & Glucose & Fructose $^{1}$ \\
\hline $\begin{array}{l}\text { Deoxycholate }(5 \mathrm{mM}) \\
\qquad(2.5 \mathrm{mM}) \\
(1.0 \mathrm{mM}) \\
\text { Chenodeoxycholate } \\
\text { Cholate } \\
\text { Taurocholate } \\
\text { Taurodeoxycholate }\end{array}$ & $\begin{array}{l}+25.30 \pm 2.37(7) \\
+23.99 \pm 0.68(13) \\
+32.77 \pm 2.37(7) \\
+31.48 \pm 2.11 \\
+28.46 \pm 2.29 \\
+29.13 \pm 1.11 \\
+30.15 \pm 1.33\end{array}$ & $5 \cdot 70 \pm 1.08$ \\
\hline
\end{tabular}

Table II Effect of different bile salts on glucose and fructose absorption in jejunum

${ }^{1}$ Initial solutions contained $20 \mathrm{mM}$ fructose. Abbreviations as in Table I.

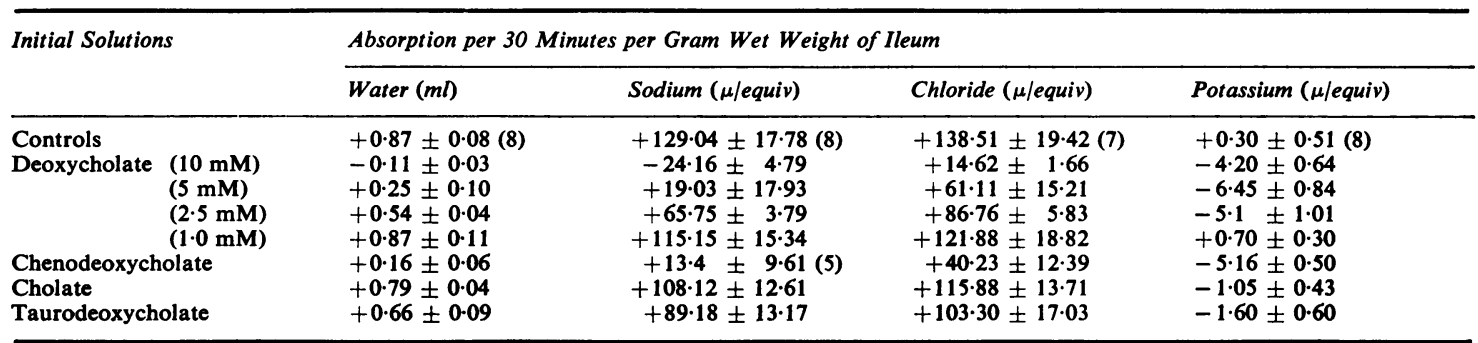

Table III Effects of different bile salts on fluid and electrolyte absorption in ileum

Abbreviations as in Table I.

significant inhibition of water, sodium, and chloride occurred at $2.5 \mathrm{mM}$ (P values $<0.01,<0.01,<0.05$ respectively) and $5 \mathrm{mM}$ deoxycholate ( $\mathrm{P}$ values $<0.002,<0.002,<0.05$ respectively) a concentration of $10 \mathrm{mM}$ was needed to inhibit absorption completely. As in jejunum the response to equimolar concentrations of deoxycholate and chenodeoxycholate was essentially the same, whereas cholate and taurodeoxycholate were ineffective in ileum.

As in jejunum, secretion of potassium occurred with the free dihydroxy bile salts.

There was no difference between sodium and chloride transport in the control animals; in contrast to the jejunum, however, chloride transport was significantly less impaired than that of sodium by $2.5 \mathrm{mM}$ deoxycholate ( $P$ by paired $t$ test $<0.02$ ), and this difference was even gieater at $5 \mathrm{mM}$ deoxycholate and chenodeoxycholate ( $P$ by paired $t$ test $<0.001$ ).

\section{REVERSIBILITY EXPERIMENTS}

The results are summarized in Table IV. The two sets of control observations shown are not significantly different $(P>0 \cdot 1)$.

Some improvement in water and sodium absorp- 


\begin{tabular}{|c|c|c|c|}
\hline \multirow[t]{2}{*}{ Initial Solution } & \multirow[t]{2}{*}{ Component } & \multicolumn{2}{|c|}{ Absorption per 20 Minutes per Gram Wet Weight of Jejunum } \\
\hline & & $\begin{array}{l}\text { Immediately after Exposure to } \\
\text { Initial Solution }\end{array}$ & $\begin{array}{l}\text { After Recovery (2-3 hr) from } \\
\text { Exposure to Initial Solution }\end{array}$ \\
\hline $\begin{array}{l}\text { Control } \\
1 \mathrm{mM} \text { Deoxycholate } \\
5 \mathrm{mM} \text { Deoxycholate }\end{array}$ & $\begin{array}{l}\text { Water (ml) } \\
\text { Sodium ( } \mu / \text { equiv) } \\
\text { Water } \\
\text { Sodium } \\
\text { Water } \\
\text { Sodium }\end{array}$ & $\begin{aligned}+0.39 & \pm 0.04(21)^{1} \\
+53.6 & \pm 10.02(12)^{1} \\
+0.28 & \pm 0.05(5) \\
+34.60 & \pm 6.85 \\
-0.32 & \pm 0.02(5) \\
-65.40 & \pm 8.53\end{aligned}$ & $\begin{aligned}+0.53 & \pm 0.05 \\
+61.16 & \pm 2.54 \\
+0.65 & \pm 0.05(5) \\
+84.22 & \pm 9.16(5) \\
+0.28 & \pm 0.03 \\
+37.93 & \pm 5.02\end{aligned}$ \\
\hline
\end{tabular}

Table IV Reversibility of effects of deoxycholate on water and sodium absorption in jejunum

'Values obtained with initial control solution as shown in Table I.

Abbreviations as in Table I.

tion was immediately apparent, but following a period of recovery absorption had reverted completely to normal at $1 \mathrm{mM}$, and considerable further improvement occurred at $5 \mathrm{mM}$ deoxycholate though there was still a significant difference compared to the controls $(P<0.001)$.

The inhibitory effect of $5 \mathrm{mM}$ deoxycholate on glucose transport (Table II) was immediately and completely reversible $(41 \cdot 3 \pm 3 \cdot 4 \mathrm{mMoles} / 20$ minutes/ $\mathrm{g}$ wet weight; $\mathrm{n}=6$ ).

\section{HISTOLOGICAL EXAMINATION}

Figures 3 and 4 show the light microscopical appearances of jejunal mucosa exposed to 2.5 and $5 \mathrm{mM}$ deoxycholate respectively, each for a period of 20 minutes. Figure 5 shows mucosa which had been exposed to $5 \mathrm{mM}$ deoxycholate and then allowed to recover for two to three hours as described in the section on methodology.
At $5 \mathrm{mM}$ deoxycholate there were slight structural abnormalities. These changes consisted of increased shedding of surface epithelial cells and were confined to the villous tips; the changes were patchy, some villi appearing entirely normal. At $2.5 \mathrm{mM}$ deoxycholate, however, there were no abnormalities compared to the control animals. Moreover, after a period of recovery, the structural changes produced by $5 \mathrm{mM}$ deoxycholate had disappeared, and the mucosal appearances had reverted to normal.

\section{Discussion}

Our studies show that the free dihydroxy bile salts inhibit absorption of fluid and electrolytes in the small intestine, and induce secretion at higher concentrations, the jejunum being more sensitive than the ileum. These effects were dependent on the

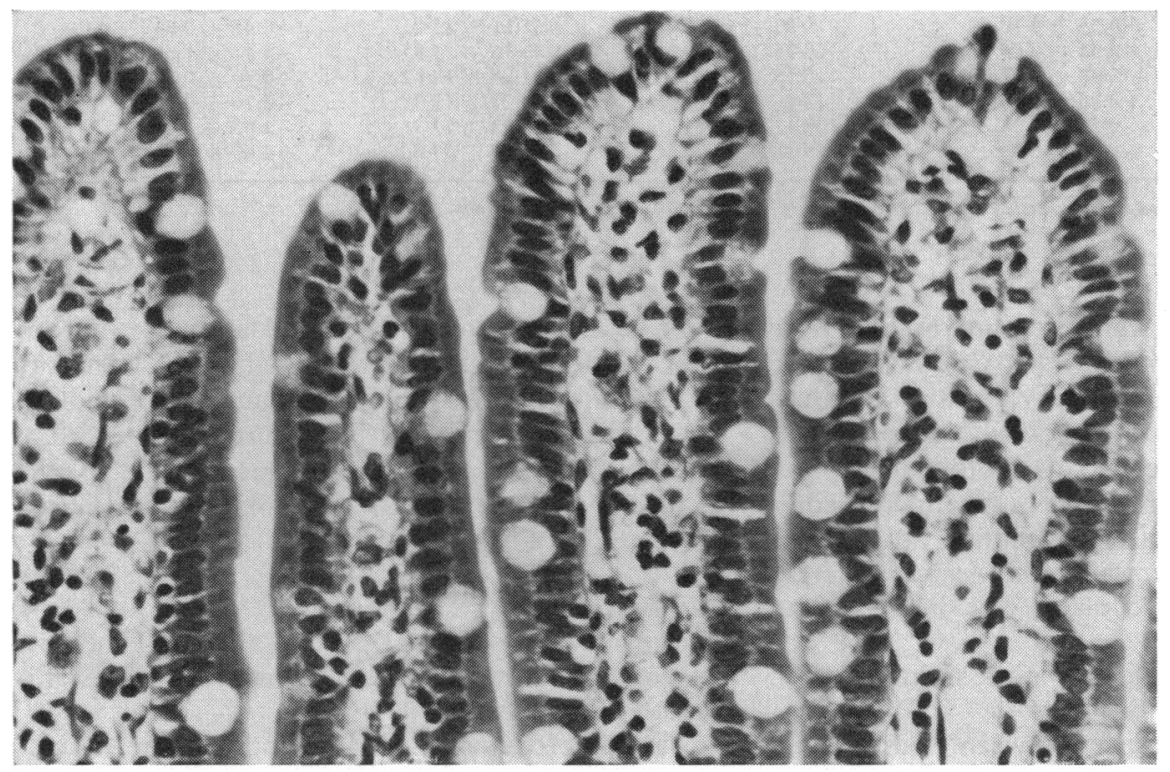

Fig. 3 Jejunal mucosa after exposure to $2.5 \mathrm{mM}$ deoxycholate for 20 minutes (haematoxylin and eosin $\times 375)$. 


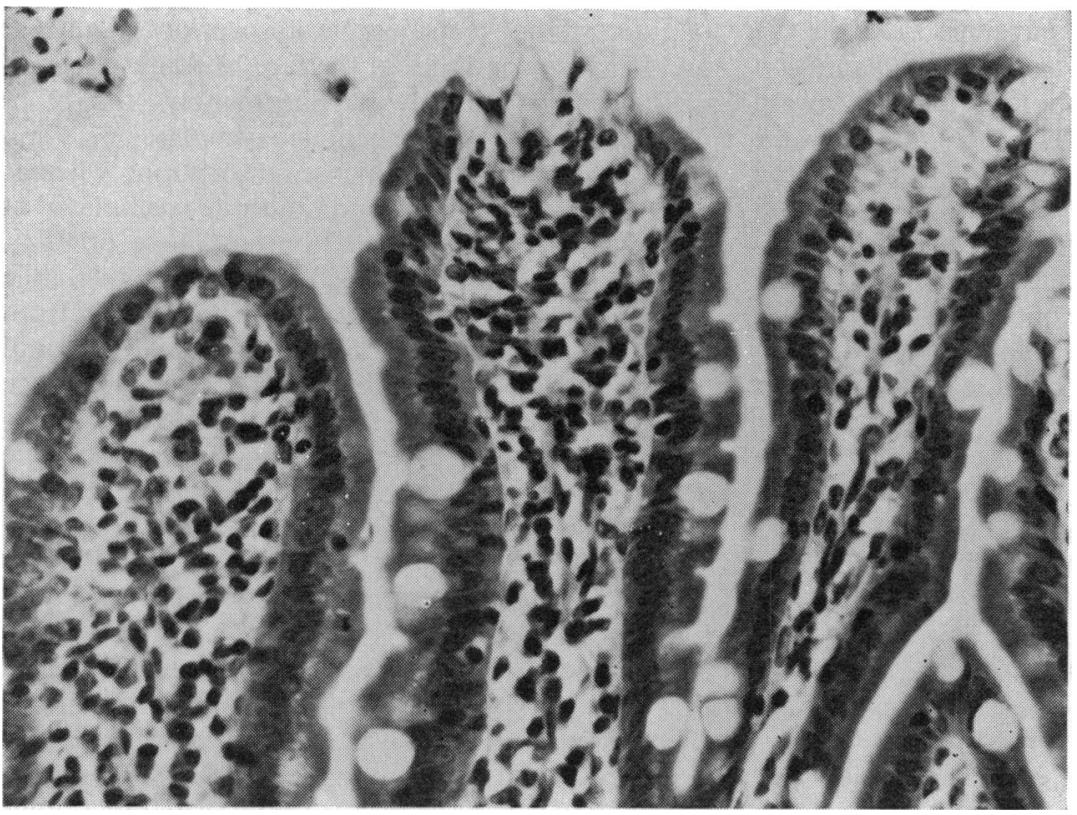

Fig. 4 Jejunal mucosa after exposure to $5 \mathrm{mM}$ deoxycholate for 20 minutes (haematoxylin and eosin $\times 375$ ).

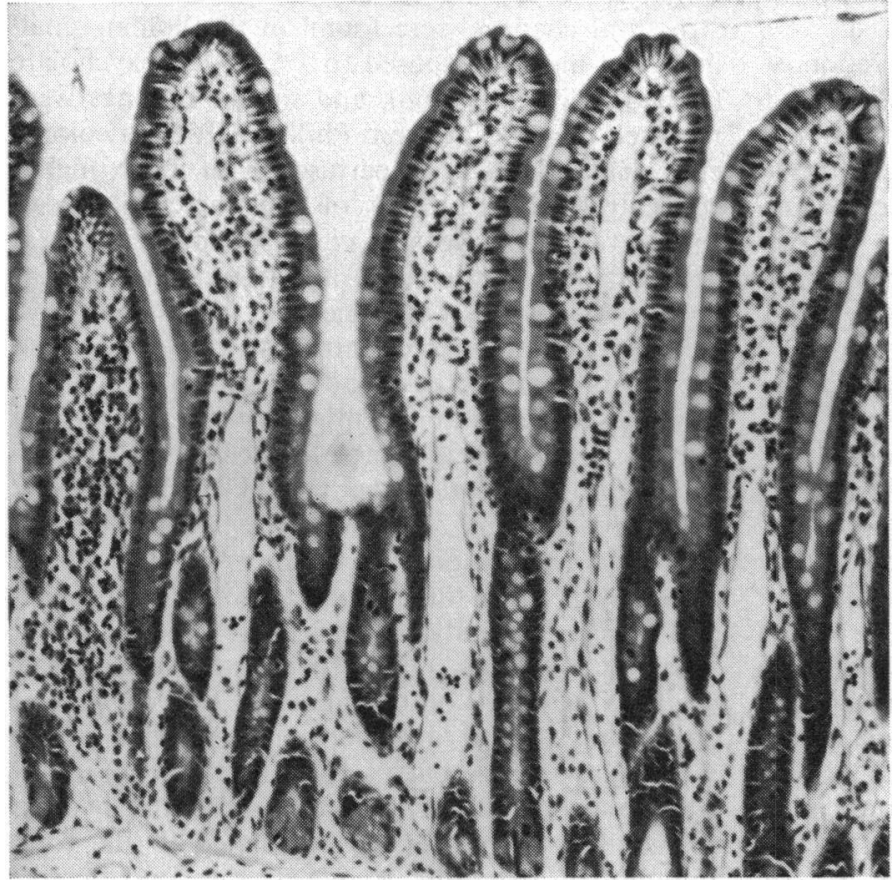

Fig. 5 Jejunal mucosa after two to three hours' recovery from exposure to $5 \mathrm{mM}$ deoxycholate for 20 minutes (haematoxylin and eosin $\times 150$ ).

intraluminal concentration of bile salts, and were associated with obvious mucosal damage only at the highest concentration of deoxycholate $(5 \mathrm{mM})$ tested. Both the functional and structural changes were rapidly reversible. In contrast, the trihydroxy bile acid, cholic acid, failed to induce secretion whether present in the free or conjugated form, but the free form produced slight inhibition of absorption at a concentration of $5 \mathrm{mM}$. These effects of the free dihydroxy and trihydroxy bile salts on fluid and electrolyte absorption were not observed with the taurine conjugates. 
Teem and Phillips (1972) have reported on the effects of different bile salts on water absorption in hamster jejunum in vivo but we are not aware of any studies reporting their effects on water absorption in ileum, or on ionic transport in any region of the small intestine. These workers found that the unconjugated dihydroxy bile salts (deoxycholate and chenodeoxycholate) inhibited water absorption and, at higher concentrations (similar to those used in the present study), induced secretion of fluid into the lumen. In contrast to our findings, deoxycholate conjugates had a similar effect, whereas chenodeoxycholate conjugates were ineffective; cholate and its conjugates were also found to be ineffective. The same group of workers (Mekhjian and Phillips, 1970; Mekhjian et al, 1971) have also shown that the conjugates of deoxycholic acid inhibit fluid absorption in the colon of both dog and man. Again they found cholic acid to be ineffective in the colon even in concentrations as high as $10 \mathrm{mM}$. The differences between these observations and our findings require further elucidation. Regional differences in bile salt sensitivity, species specificity, and differences in methodological techniques may be partly responsible.

The free dihydroxy bile salts induced secretion of potassium both in the ileum and jejunum, and similar results have been reported for the large intestine in man (Mekhjian et al, 1971). Further studies are in progress to define the mechanisms responsible for this effect.

In the control animals, in both jejunum and ileum, there was no significant difference between chloride and sodium transport rates; this was also the case in jejunum at 2.5 and $5 \mathrm{mM}$ deoxycholate. In the ileum, however, chloride absorption was significantly less impaired than that of sodium at 2.5 and $5 \mathrm{mM}$ deoxycholate, and at $5 \mathrm{mM}$ chenodeoxycholate. It is possible that the separate chloridebicarbonate exchange mechanism in the ileum (Hubel, 1967) is less susceptible to the inhibitory effects of the unconjugated dihydroxy bile salts.

Gracey and his colleagues (Gracey et al, 1971a) have recently demonstrated that Arbutin uptake can be reversibly inhibited in vitro in the small intestine by concentrations of deoxycholate as low as $0.5 \mathrm{mM}$, and the same workers have shown inhibition of both arbutin and glucose transport by $1 \mathrm{mM}$ concentrations in the same species in vivo (Gracey et al, 1971b). We have been unable to show inhibitory effects with such low concentrations of deoxycholate, and this may be accounted for by differences in methedological techniques. With higher concentrations of deoxycholate $(5 \mathrm{mM})$, however, we have demonstrated significant inhibition of both glucose and fructose transport. It is of interest that considerable absorption of glucose and fructose continues in the face of frank secretion of fluid and electrolytes. Surprisingly, the other dihydroxy bile salt, chenodeoxycholate, had no effect whatsoever on glucose absorption, whereas cholate, taurocholate and taurodeoxycholate at $5 \mathrm{mM}$ resulted in slight inhibition. These observations suggest that the mechanisms by which bile salts inhibit monosaccharide transport differ from those which inhibit fluid and electrolyte absorption.

The exact mechanisms by which bile salts influence various transport processes are not clearly understood. In vitro, the unconjugated dihydroxy bile acids produce considerable tissue disruption (Dawson and Isselbacher, 1960; Donaldson, 1965; Low-Beer, Schneider, and Dobbins, 1970), and their inhibitory effects on transport processes have been attributed to irreversible tissue damage (Dietschy, 1967). These conclusions cannot be extended to the effects of these compounds in vivo, since their inhibitory effects are not invariably accompanied by structural alterations, and are rapidly reversible (Tabaqchali, Hatziannou, and Booth, 1968; Mekhjian and Phillips, 1970; Gracey et al, 1971c). No ultrastructural changes were found in the human small intestinal mucosa exposed to $1.5 \mathrm{mM}$ deoxycholate (Tabaqchali et al, 1968), and similar findings were reported by Mekhjian and Phillips (1970) in colonic epithelial cells of dogs perfused with much higher concentrations $(10 \mathrm{mM})$ of the same bile acid. In contrast, Low-Beer et al (1970) found mucosal abnormalities in the small intestine of guinea pigs and hamsters following one-hour perfusions with solutions containing concentrations of deoxycholate as low as $1 \mathrm{mM}$. Teem and Phillips (1972), using a similar concentration $(1 \mathrm{mM})$ of the unconjugated dihydroxy salts, were unable to demonstrate structural abnormalities in the jejunal mucosa of the hamster following 45-minute perfusion periods; higher concentrations $(4 \mathrm{mM})$ produced villous tip damage of a similar nature to that observed in the present study. Low-Beer et al (1970) and Teem and Phillips (1972) perfused the bile salt solutions at rates of 4.5 and $0.1 \mathrm{ml}$ per minute respectively in the hamster jejunum. The differences between the effects of $1 \mathrm{mM}$ unconjugated dihydroxy bile salts on mucosal structure in these two studies may therefore be related to the total amounts of bile salts to which the mucosa was exposed. The rapid structural recovery of mucosa exposed to $5 \mathrm{mM}$ deoxycholate which we observed has not previously been documented, although Fry and Staffeldt (1964) have reported reversible histological damage in mice during long-term feeding experiments with $2 \%$ deoxycholate.

Bile salts are surface-active substances and 
Mekhjian et al (1971) have speculated that their effect on large intestinal function may be due to inhibition of membrane-bound $\mathrm{Na}$ ATPase, either by altering enzyme configuration, competitively inhibiting binding of inorganic phosphate, or by altering lipid-protein interactions in cell membranes. It seems unlikely, however, that such a mechanism can satisfactorily explain why some bile salts had little or no effect on fluid and electrolyte absorption in the present study. Further work is required to define the mechanisms by which bile salts interfere with intestinal transport processes, and the relationship between their structure and their effects on transport.

In man little is known of the absorption of fluid and electrolytes in conditions where there is bacterial overgrowth in the small intestine (Gracey, 1971). Concentrations of unconjugated bile acids similar to those used in the present study have been reported in patients with the stagnant loop syndrome (Tabaqchali et al, 1968), and the presence of fiee bile acids has also been demonstrated in the proximal small intestine of infants with fluid diarrhoea and monosaccharide malabsorption (Gracey, Burke, and Anderson, 1969). Our findings may be relevant to conditions of bacterial overgrowth in the small intestine in man, and the possibility that bacterially degraded bile salts may result in secretion of fluid and electrolytes both in adults and infants with unexplained diarrhoeal syndromes requires further investigation.

We are grateful to Dr A. M. Dawson for his advice, and to Messrs L. Ellam and A. Kingston for technical assistance. We thank the Wellcome Trust for continued financial support.

\section{References}

Dawson, A. M., and Isselbacher, K. J. (1960). Studies on lipid metabolism in the small intestine with observations on the role of bile salts. J. clin. Invest., 39, 730-740.

Dietschy, J. M. (1967). Effects of bile salts on intermediate metabolism of the intestinal mucosa. Fed. Proc., 26, 1589-1598.

Donaldson, R. M., Jr. (1965). Studies on the pathogenesis of steatorrhea in the blind loop syndrome. J. clin. Invest., 44, 1815-1825.
Forth, W., Rummel, W., and Glasner, H. (1966). Zur resorptionshemmenden Wirkung von Gallensäuren. Naunyn-Schmiedeberg's Arch. exp. Path. Pharmak., 254, 364-380.

Fry, R. J. M., and Staffeldt, E. (1964). Effect of a diet containing sodium deoxycholate on the intestinal mucosa of the mouse. Nature (Lond.), 203, 1396-1398.

Gracey, M. (1971). Intestinal absorption in the 'contaminated smallbowel syndrome'. Gut, 12, 403-410.

Gracey, M., Burke, V., and Anderson, C. M. (1969). Association of monosaccharide malabsorption with abnormal smallintestinal flora. Lancet, 2, 384-385.

Gracey, M., Burke, V., and Oshin, A. (1971 a). Reversible inhibition of intestinal active sugar transport by deconjugated bile salt in vitro. Biochim. biophys. Acta (Amst.), 225, 308-314.

Gracey, M., Burke, V., and Oshin, A. (1971b). Influence of bile salts on intestinal sugar transport in vivo. Scand. J. Gastroent., 6, 273-276.

Gracey, M., Burke, V., Oshin, A., Barker, J., and Glasgow, E. F. (1971). Bacteria, bile salts, and intestinal monosaccharide malabsorption. Gut, 12, 683-692.

Harries, J. T., and Sladen, G. E. (1971). Effects of bile acids on small intestinal absorption of glucose, water, and sodium. Gut, 12, 855

Hers, H. G., Beaufays, H., and de Duve, C. (1953). L'analyse simultanée des hexoses, des trioses et de leurs esters phosphorés. Biochim. biophys. Acta (Amst.), 11, 416-426.

Hubel, K. A. (1967). Bicarbonate secretion in rat ileum and its dependence on Intraluminal chloride. Amer. J. Physiol., 213, 1409-1413.

Hyden, S. (1956). A turbidometric method for the determination of higher polyethylene glycols in biological materials. $K$. LantbrHögsk. Anner., 22, 139-145.

Low-Beer, T. S., Schneider, R. E., and Dobbins, W. O. (1970). Morphological changes of the small-intestinal mucosa of guinea pig and hamster following incubation in vitro and perfusion in vivo with unconjugated bile salts. Gut, 11, 486-492.

Mahy, B. W. J., Rowson, K. E. K., Salaman, M. H., and Parr, C. W. (1964). Plasma enzyme levels in virus-infected mice. Virology, 23, 528-541.

Mekhjian, H. S., and Phillips, S. F. (1970). Perfusion of the canine colon with unconjugated bile acids. Effect on water and electrolyte transport, morphology and bile acid absorption. Gastroenterology, 59, 120-129.

Mekhjian, H. S., Phillips, S. F., and Hofmann, A. F. (1971). Colonic secretion of water and electrolytes induced by bile acids: perfusion studies in man. J. clin. Invest., 50, 1569-1577.

Pope, J. L., Parkinson, T. M., and Olson, J. A. (1966). Action of bile salts on the metabolism and transport of water-soluble nutrients by perfused rat jejunum in vitro. Biochim. biophys. Acta (Amst.), 130, 218-232.

Roe, J. H., Epstein, J. H., and Goldstein, N. P. (1949). A photometric method for the determination of inulin in plasma and urine. J. biol. Chem., 178, 839-845.

Tabaqchali, S., Hatzioannou, J., and Booth, C. C. (1968). Bile-salt deconjugation and steatorrhoea in patients with the stagnantloop syndrome. Lancet, 2, 12-16.

Teem, M. V., and Phillips, S. F. (1972). Perfusion of the hamster jejunum with conjugated and unconjugated bile acids: inhibition of water absorption and effects on morphology. Gastroenterology, 62, 261-267. 